\title{
The impact of vitamin D supplementation on body fat mass in elite male collegiate athletes
}

\author{
Itaru Kawashima 1* (D), Takashi Tsukahara², Ryosuke Kawai , Takafumi Mizuno', Shinya Ishizuka', \\ Hideki Hiraiwa ${ }^{1}$ and Shiro Imagama ${ }^{1}$
}

\begin{abstract}
Background: Whether vitamin D supplementation has any effect on body fat percentage, especially among elite athletes, remains unclear. The aim of this study was to evaluate the effect of vitamin D supplementation on serum vitamin D level in elite male collegiate athletes and to analyze its effect on body fat percentage.

Methods: We enrolled a total of 42 elite male collegiate athletes in this prospective cohort study. In March 2020, body composition monitoring and blood test were performed. All athletes were provided with vitamin D3 supplement tablets of $25 \mu \mathrm{g} /$ day. The use of the supplement was dependent on athletes' preference. During the study period, their club activities were stopped for 2 months due to the coronavirus disease 2019 outbreak. A second examination, similar to the first one, was performed after approximately 3 months. Supplement usage by each athlete was also confirmed. The participants were divided into a non-supplement group (without supplementation, $\mathrm{n}=15$ ) and a supplement group (with supplementation, $\mathrm{n}=27$ ).

Results: Regarding baseline data at initial examination, the non-supplement and supplement groups showed significant differences in the mean body fat percentage $(9.0 \%$ and $12.1 \%$, respectively; $P=0.03)$ and serum $25(\mathrm{OH}) \mathrm{D}$ level (22.7 and $18.5 \mathrm{ng} / \mathrm{mL}$, respectively, $P=0.02$ ). At the time of the second examination, there were no significant differences in the results of both the groups. In terms of mean change value from the first to the second examination, there were significant differences in body fat percentage (1.9 and $0.2 \%$, respectively, $P=0.02)$ and serum $25(\mathrm{OH}) \mathrm{D}$ level $(1.7$ and $7.2 \mathrm{ng} / \mathrm{mL}$, respectively, $P<0.001$ ) between the two groups.

A significant negative correlation was observed between the change ratio of body fat percentage and change value of serum 25(OH)D level $(r=-0.37, P=0.02)$.

Conclusions: Vitamin D supplementation of $25 \mu \mathrm{g} /$ day significantly increased the serum $25(\mathrm{OH}) \mathrm{D}$ level in elite male collegiate athletes. Vitamin D supplementation may play a role in maintaining athletes' body fat percentage under circumstances where sports activity has decreased.
\end{abstract}

Keywords: Vitamin D, Supplementation, Body fat percentage, Body composition, Male collegiate athletes, COVID-19

\footnotetext{
*Correspondence: itaru.kawashima@gmail.com

${ }^{1}$ Department of Orthopaedic Surgery, Nagoya University Graduate

School of Medicine, 65 Tsurumai, Showa-ku, Nagoya, Aichi 466-8550, Japan

Full list of author information is available at the end of the article
}

\section{Background}

Vitamin D has proposed roles not only in the inflammatory response, immunity, neuromuscular function, and reduction of incidence of carcinomas but also in bone health. Vitamin D deficiency has been correlated to the risk of bone stress fracture, a common overuse injury in permits use, sharing, adaptation, distribution and reproduction in any medium or format, as long as you give appropriate credit to the original author(s) and the source, provide a link to the Creative Commons licence, and indicate if changes were made. The images or other third party material in this article are included in the article's Creative Commons licence, unless indicated otherwise in a credit line to the material. If material is not included in the article's Creative Commons licence and your intended use is not permitted by statutory regulation or exceeds the permitted use, you will need to obtain permission directly from the copyright holder. To view a copy of this licence, visit http://creativecommons.org/licenses/by/4.0/. The Creative Commons Public Domain Dedication waiver (http://creativeco mmons.org/publicdomain/zero/1.0/) applies to the data made available in this article, unless otherwise stated in a credit line to the data. 
elite athletes [1-5]. Therefore, the importance of adequate vitamin D levels in athletes has become a trending topic of interest [6]. Athletes tend to have an increased risk of vitamin D deficiency; however, it has been reported in the general population as well [7-9]. Vitamin D supplementation seems to have a possibility to improve vitamin D deficiency in athletes. However, the validity of this idea is unknown.

Furthermore, ideal weight control is perceived as an advantage in athletes [10]. Vitamin D level is inversely related to body weight, body mass index (BMI), and body fat percentage [11-13]. Golzarand et al. [14] reported that vitamin D supplementation had no effect on body fat percentage. In contrast, Salepour et al. [15] showed that increasing vitamin $\mathrm{D}$ levels by supplementation led to body fat mass reduction. Therefore, whether vitamin D supplementation has an effect on body fat percentage especially in elite athletes remains unclear.

This prospective study was aimed to evaluate the effect of vitamin D supplementation on serum vitamin D level in elite male collegiate athletes and to analyze its effect on body fat percentage. The secondary aim of this study was to analyze the association between the change ratio of body fat percentage and change value of serum vitamin D level. We hypothesized that vitamin D supplementation would increase serum vitamin D level and would be related to lower body fat percentage. We also hypothesized that a negative correlation was observed between the change ratio of body fat percentage and change value of serum vitamin D level.

\section{Methods}

\section{Participant selection}

This study was approved by the Institutional Review Board and Ethics Committee of our institution before the study. A prospective analysis was performed.

The inclusion criteria for the participants were as follows: they should be collegiate athletes who are members of the national-champion-level teams in our institution and should be of the male sex. The exclusion criteria were as follows: (1) use of any medications or supplementation and (2) inability to participate in all examinations.

Participation was voluntary, and the participants were provided a thorough explanation of the objectives, methods, and ethical considerations of this study. Written informed consent was obtained from all participants included in the study.

\section{First examination}

In March 2020, all athletes' BMI, body fat percentage, and bone mass were measured using MC-980A-N plus (Tanita Corporation, Tokyo, Japan), a body composition analyzer.
Blood samples were collected to check the serum calcium, phosphorus, and $25(\mathrm{OH}) \mathrm{D}$ levels on the same day as the body composition monitoring. Serum 25(OH) $\mathrm{D}$ levels were analyzed using electrochemiluminescence immunoassay kits by SRL, Inc. (Tokyo, Japan). Serum calcium levels were measured through an enzymatic method using phospholipase D. Serum inorganic phosphate levels were measured through an enzymatic method using purine nucleoside phosphorylase.

\section{Supplementation and second examination}

When all athletes were informed of the first examination results, they were provided vitamin D3 supplement tablets in the form of cholecalciferol $25 \mu \mathrm{g} /$ day and Vitamin D Super 1000 IU Nature Made by Otsuka Pharmaceutical Co. (Tokyo, Japan) to be taken for 3 months. The use of the supplement was dependent on athletes' preference without any force. Initially, the second examination similar to the first examination was scheduled 3 months after the first examination. Unexpectedly, the coronavirus disease 2019 (COVID-19) outbreak occurred, and their club activities were banned for 2 months from 1 month after the first examination.

The second examination was conducted 1 week after the ban on club activities was lifted. Body composition monitoring and blood test were performed similar to those in the first examination. Simultaneously, it was confirmed whether the supplement was used by each athlete.

The participants were divided into two groups according to vitamin D supplementation: the non-supplement group and the supplement group.

\section{Statistical analysis}

All statistical analyses were performed with EZR (Saitama Medical Center, Jichi Medical University, Saitama, Japan), a graphical user interface for R (The R Foundation for Statistical Computing, Vienna, Austria) [16]. More precisely, it is a modified version of R Commander designed to add statistical functions frequently used in biostatistics. Student's t-test and Fisher's exact test were used to compare the data of the two groups. Paired t-test was used to compare the data of the first and second examinations in each group. Pearson's product moment correlation statistic was used to assess the correlation between the change ratio of body fat percentage (difference in the body fat percentage between the first and second examination) and the change in serum vitamin $\mathrm{D}$ levels (difference in serum vitamin $D$ levels between the first and second examination). $P$-values $<0.05$ were considered statistically significant. 


\section{Results}

Fifty elite male collegiate athletes participated in the first examination (Fig. 1). Eight athletes were excluded because they could not participate in the second examination. Thus, 42 participants, including 24 hockey players and 18 fencing players, were included in the analysis: 15 participants in the non-supplement group and 27 participants in the supplement group.

In terms of baseline data of the first examination, there was a significant difference in the mean body fat percentage between the groups (Table 1; 9.0\% $\pm 1.9 \%$ and $12.1 \% \pm 3.8 \%$, respectively; $P=0.03$ ). Moreover, the non-supplement group had a significantly higher serum $25(\mathrm{OH}) \mathrm{D}$ level than the supplement group $(22.7 \pm 5.7$ and $18.5 \pm 4.9 \mathrm{ng} / \mathrm{mL}$, respectively, $P=0.02$ ). There were no significant differences in participants' age, height, BMI, bone mass, lean body mass, serum calcium level, and serum phosphorus level between the two groups.

Significant differences were observed between the pre- and post-supplement BMI, body fat percentage, and serum $25(\mathrm{OH}) \mathrm{D}$ level in all athletes and the

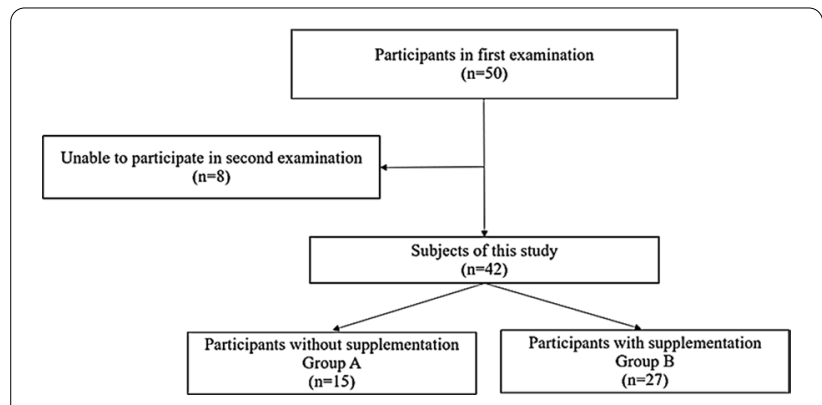

Fig. 1 Flowchart of participant selection

Table 1 Baseline characteristics of the participants

\begin{tabular}{|c|c|c|c|c|}
\hline & All athletes $(n=42)$ & $\begin{array}{l}\text { Non-supplement group } \\
(n=15)\end{array}$ & $\begin{array}{l}\text { Supplement group } \\
(n=27)\end{array}$ & $P$ value \\
\hline Age, y & $20 \pm 1$ & $20 \pm 1$ & $20 \pm 1$ & 0.3 \\
\hline Height, cm & $172 \pm 5$ & $171 \pm 6$ & $172 \pm 5$ & 0.7 \\
\hline Hockey/Fencing & $24 / 18$ & $11 / 4$ & $13 / 14$ & 0.2 \\
\hline \multicolumn{5}{|l|}{ Body composition } \\
\hline $\mathrm{BMI}, \mathrm{kg} / \mathrm{m}^{2}$ & $21.4 \pm 2.6$ & $20.4 \pm 1.1$ & $22.0 \pm 3.0$ & 0.06 \\
\hline Body fat percentage, $\%$ & $11.0 \pm 3.5$ & $9.0 \pm 1.9$ & $12.1 \pm 3.8$ & 0.005 \\
\hline Bone mass, kg & $2.9 \pm 0.3$ & $2.8 \pm 0.2$ & $3.0 \pm 0.3$ & 0.1 \\
\hline Lean mass, kg & $56.1 \pm 5.0$ & $54.5 \pm 3.7$ & $57.1 \pm 5.4$ & 0.1 \\
\hline \multicolumn{5}{|l|}{ Laboratory results } \\
\hline Serum $25(\mathrm{OH}) \mathrm{D}, \mathrm{ng} / \mathrm{mL}$ & $20.0 \pm 5.5$ & $22.7 \pm 5.7$ & $18.5 \pm 4.9$ & 0.02 \\
\hline Serum Calcium, mg/dL & $9.8 \pm 0.3$ & $9.8 \pm 0.4$ & $9.8 \pm 0.3$ & 0.6 \\
\hline Serum Phosphorus, mg/dL & $3.5 \pm 0.5$ & $3.5 \pm 0.3$ & $3.5 \pm 0.5$ & 1.0 \\
\hline
\end{tabular}

The values are given as mean \pm standard deviation

Bold indicates statistically significant $P$ values $(P<0.05)$

$B M I$ body mass index non-supplement group $(21.4 \pm 2.6$ and $22.0 \pm 2.7$, respectively, $P=0.04 ; 11.0 \% \pm 3.5 \%$ and $11.8 \% \pm 3.5 \%$, respectively, $P=0.04 ; 20.0 \pm 5.5$ and $25.3 \pm 5.6 \mathrm{ng} /$ $\mathrm{mL}$, respectively, $P<0.001)(20.4 \pm 1.1$ and $21.1 \pm 1.3$, respectively; $P<0.001,9.0 \% \pm 1.9 \%$ and $10.9 \% \pm 2.8 \%$, respectively; $P=0.02,22.7 \pm 5.7$ and $24.4 \pm 5.5 \mathrm{ng} / \mathrm{mL}$, respectively, $P=0.005$ ) (Table 2). Moreover, significant differences were observed between the pre- and postsupplement serum $25(\mathrm{OH}) \mathrm{D}$ level in the supplement group (18.5 \pm 4.9 and $25.8 \pm 5.6$, respectively; $P<0.001$ ).

Table 2 Pre and post BMl, body fat, and serum vitamin D level in each group

\begin{tabular}{lrrc}
\hline & Pre & Post & P value \\
\hline All athletes & & & \\
BMl, kg/m² & $21.4 \pm 2.6$ & $22.0 \pm 2.7$ & $\mathbf{0 . 0 4}$ \\
Body fat percentage, \% & $11.0 \pm 3.5$ & $11.8 \pm 3.5$ & $\mathbf{0 . 0 4}$ \\
Serum 25(OH) D, ng/mL & $20.0 \pm 5.5$ & $25.3 \pm 5.6$ & $>\mathbf{0 . 0 0 1}$ \\
Non-supplement group & & & \\
BMl, kg/m² & & & \\
Body fat percentage, \% & $9.0 \pm 1.9$ & $10.9 \pm 2.8$ & $\mathbf{0 . 0 2}$ \\
Serum 25(OH) D, ng/mL & $22.7 \pm 5.7$ & $24.4 \pm 5.5$ & $\mathbf{0 . 0 0 5}$ \\
Supplement group & & & \\
BMl, kg/m & & & 0.1 \\
Body fat percentage, \% & $12.1 \pm 3.8$ & $12.3 \pm 3.8$ & 0.9 \\
Serum 25(OH) D, ng/mL & $18.5 \pm 4.9$ & $25.8 \pm 5.6$ & $>\mathbf{0 . 0 0 1}$ \\
\hline
\end{tabular}

The values are given as mean \pm standard deviation

Bold indicates statistically significant $P$ values $(P<0.05)$

$B M I$ body mass index 
However, no significant differences were found between pre- and post-supplement BMI and body fat percentage.

In terms of follow-up data of the second examination, there were no significant differences in participants' BMI, body fat percentage, bone mass, and lean body mass between the two groups (Table 3). There were also no significant differences in participants' serum $25(\mathrm{OH})$ D level, calcium level, and phosphorus level between the two groups.

In terms of change value from the first examination to the second examination, there were significant differences in body fat percentage between the groups $(1.9 \% \pm 2.6 \%$ and $0.2 \% \pm 2.0 \%$, respectively, $P=0.02)$. Moreover, change value of serum 25(OH)D level in the non-supplement group was significantly lower than that in the supplement group $(1.7 \pm 1.9$ and $7.2 \pm 5.2 \mathrm{ng} / \mathrm{mL}$, respectively, $P<0.001$ ).

A significant negative correlation was observed between the change ratio of body fat percentage and change value of serum 25(OH)D level (Fig. 2, $r=-0.37$, $P=0.02)$.

\section{Discussion}

This study might show the effectiveness of $25 \mu \mathrm{g} /$ day vitamin D supplementation, which significantly increase the serum 25(OH)D level. Change ratio of body fat percentage in athletes without vitamin D supplementation was significantly higher than those in athletes with vitamin D supplementation under the unexpected situation of ban in club activities due to the COVID-19 outbreak. Moreover, a significant negative correlation was observed between the change ratio of body fat percentage and change value of serum $25(\mathrm{OH}) \mathrm{D}$ level in entire athletes in the same period.

Vitamin D has a significant impact on bone health, immune function, and physical performance. When there is deficiency, athletes may be at an increased risk of stress fractures, respiratory infections, and muscle injuries [17]. Female Navy recruits receiving vitamin D supplementation had a $20 \%$ lower incidence of stress fractures than recruits receiving placebo [2]. Therefore, vitamin $\mathrm{D}$ levels are greatly important for athletes, and vitamin D supplementation seems to improve vitamin-Ddeficiency-related disorders in athletes.

Jung et al. [18] reported that 4 weeks of $125 \mu \mathrm{g} /$ day vitamin $\mathrm{D}$ supplementation increased the mean serum 25(OH)D level from $10.9 \mathrm{ng} / \mathrm{mL}$ to $38.4 \mathrm{ng} / \mathrm{mL}$. Similarly, this study showed that vitamin D supplementation significantly increased the mean serum $25(\mathrm{OH}) \mathrm{D}$ level. However, the amount of daily vitamin $\mathrm{D}$ supplementation was $25 \mu \mathrm{g} /$ day; therefore, the serum $25(\mathrm{OH}) \mathrm{D}$ level increase was milder than those in the previous study. Due to this mild increase, no sudden changes in blood calcium or phosphorus levels were observed.

Golzarand et al. [14] reported that vitamin D supplementation had no effect on body fat percentage. Conversely, Salepour et al. [15] reported that increasing 25(OH)D levels by vitamin D3 supplementation led to

Table 3 Comparison between the groups after intervention

\begin{tabular}{|c|c|c|c|c|}
\hline & All athletes $(n=42)$ & $\begin{array}{l}\text { Non-supplement group } \\
(n=15)\end{array}$ & $\begin{array}{l}\text { Supplement group } \\
(\mathrm{n}=27)\end{array}$ & $P$ value \\
\hline \multicolumn{5}{|l|}{ Body composition } \\
\hline Post BMl, kg/m² & $22.0 \pm 2.7$ & $21.1 \pm 1.3$ & $22.5 \pm 3.1$ & 0.1 \\
\hline Change value of $\mathrm{BMI}, \mathrm{kg} / \mathrm{m}^{2}$ & $0.6 \pm 1.9$ & $0.7 \pm 0.7$ & $0.6 \pm 2.3$ & 0.8 \\
\hline Post body fat percentage, $\%$ & $11.8 \pm 3.5$ & $10.9 \pm 2.8$ & $12.3 \pm 3.8$ & 0.2 \\
\hline Change ratio of body fat percentage, $\%$ & $0.8 \pm 2.4$ & $1.9 \pm 2.6$ & $0.2 \pm 2.0$ & 0.02 \\
\hline post Bone mass, kg & $2.9 \pm 0.2$ & $2.9 \pm 0.2$ & $3.0 \pm 0.3$ & 0.3 \\
\hline Change value of bone mass, $\mathrm{kg}$ & $0.0 \pm 0.1$ & $0.0 \pm 0.1$ & $0.0 \pm 0.1$ & 0.1 \\
\hline Post lean mass, kg & $56.4 \pm .4 .7$ & $55.2 \pm .3 .6$ & $57.1 \pm 5.2$ & 0.2 \\
\hline Change value of lean mass, kg & $0.3 \pm .1 .7$ & $0.7 \pm .1 .6$ & $0.0 \pm 1.7$ & 0.2 \\
\hline \multicolumn{5}{|l|}{ Laboratory results } \\
\hline Post serum $25(\mathrm{OH}) \mathrm{D}, \mathrm{ng} / \mathrm{mL}$ & $25.3 \pm 5.6$ & $24.4 \pm 5.5$ & $25.8 \pm 5.6$ & 0.4 \\
\hline Change value of serum $25(\mathrm{OH}) \mathrm{D}, \mathrm{ng} / \mathrm{mL}$ & $5.3 \pm 5.1$ & $1.7 \pm 1.9$ & $7.2 \pm 5.2$ & $>0.001$ \\
\hline Post serum Calcium, mg/dL & $9.6 \pm 0.4$ & $9.5 \pm 0.3$ & $9.7 \pm 0.4$ & 0.2 \\
\hline Change value of serum Calcium, mg/dL & $-0.1 \pm 0.5$ & $-0.3 \pm 0.6$ & $-0.1 \pm 0.4$ & 0.2 \\
\hline Post serum Phosphorus, mg/dL & $3.3 \pm 0.4$ & $3.4 \pm 0.4$ & $3.3 \pm 0.4$ & 0.3 \\
\hline Change value of serum Phosphorus, mg/dL & $-0.2 \pm 0.6$ & $-0.1 \pm 0.5$ & $-0.2 \pm 0.6$ & 0.4 \\
\hline
\end{tabular}

The values are given as mean \pm standard deviation

Bold indicates statistically significant $P$ values $(P<0.05)$

$B M /$ body mass index 


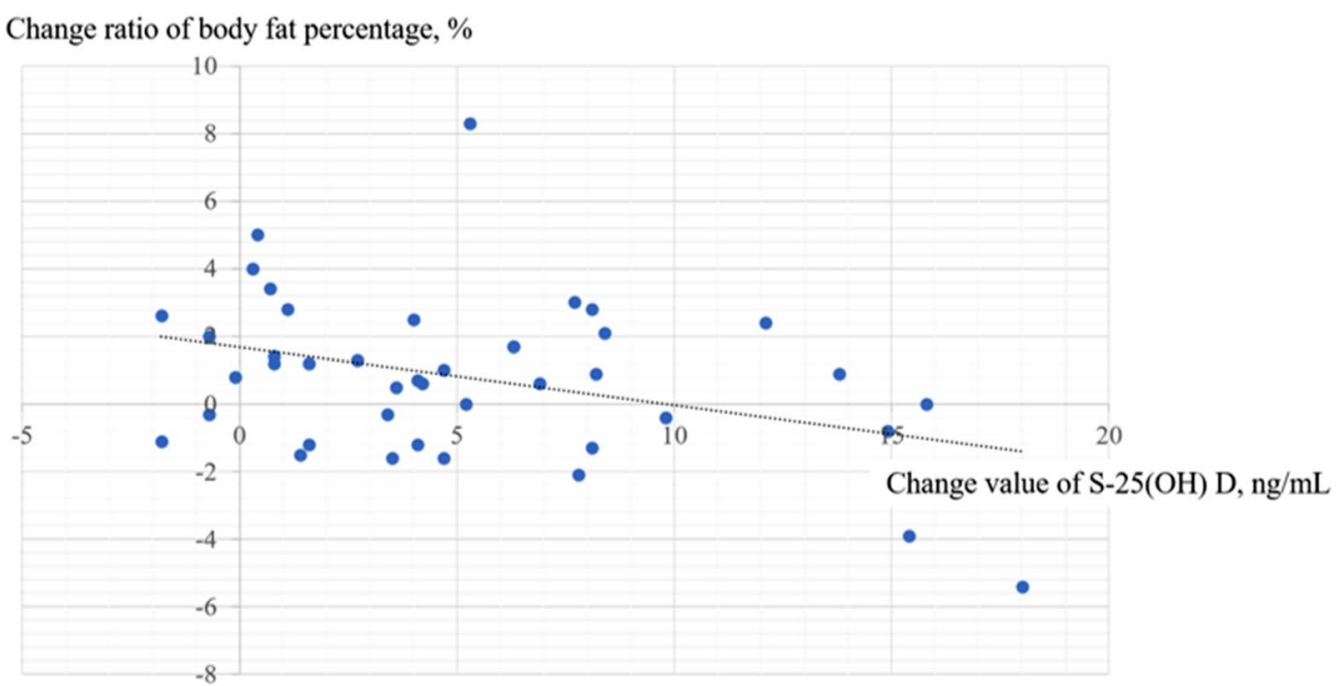

Fig. 2 Correlation between the change ratio in body fat percentage and value in serum 25(OH)D level

body fat mass reduction. In contrast, Renzo et al. [19] reported that the perception of weight gain was observed in $48.6 \%$ of the population during behavioral restriction due to the COVID-19 outbreak. During this study, a state of emergency was declared due to the COVID-19 outbreak, and sports activity was stopped, and athletes without supplementation gained body fat percentage of $1.9 \%$. Conversely, athletes with supplementation had almost unchanged conditions and maintained their body composition, and as a result, there was a significant difference in the change value between the two groups.

Arunabh et al. [20] reported that the percentage of body fat is inversely related to the serum $25(\mathrm{OH}) \mathrm{D}$ level. Worstman et al. [21] explained that vitamin D insufficiency associated with obesity is due to decreased bioavailability of vitamin D from cutaneous and dietary sources due to its deposition in body fat compartments. However, it was reported that increasing vitamin D levels by supplementation led to body fat mass reduction in a randomized controlled trial [15]. Similarly, this study showed that vitamin D supplementation might be effective in maintaining body fat. Moreover, the percentage of body fat is inversely related to the serum $25(\mathrm{OH}) \mathrm{D}$ level in all the athletes included in the present study. Increased serum $25(\mathrm{OH}) \mathrm{D}$ level might suppress the increase in body fat percentage.

This study had several serious limitations. First, participants were not randomly assigned to the two groups. Therefore, selection bias might have influenced the outcomes. This may have also resulted in the differences in baseline body fat percentage and serum 25(OH)D levels between the two groups of participants'. We believe this might be because of the lower serum $25(\mathrm{OH}) \mathrm{D}$ levels obtained on the first examination. More athletes might have taken the vitamin D supplement after they were informed of the first examination results. Moreover, body fat percentage is reported to be inversely related to serum 25(OH)D level [20]. These differences could have affected the change in the body fat percentage and the change in serum $25(\mathrm{OH}) \mathrm{D}$ level between the groups. Another possibility was that people who decided to take the supplement were in general healthier, since taking the supplement was voluntary, and could have had healthier lifestyles. Second, seasonal changes were not investigated. Maruyama-Nagao et al. [22] reported that athletes' serum 25(OH)D levels were lower in March and higher in June. This might have also caused the increased serum $25(\mathrm{OH}) \mathrm{D}$ levels, even in the non-supplement group. Third, confirmation of the supplementation depended on each athletes' self-report. This might have introduced errors and precise adherence was not determined. Fourth, the athletes' food intake data were not analyzed. Food intake has an impact on the parameters measured and would have thus strongly affected the results of this study. Fifth, all the participants of the study were male. Body fat percentage is known to vary between female and male athletes. As this study design was not a randomized control study, only male athletes were included to avoid a big bias of sex difference. However, this would affect the generalizability of the results. Lastly, the sample size was relatively small.

\section{Conclusions}

This study showed that $25 \mu \mathrm{g} /$ day vitamin D supplementation significantly increased the serum $25(\mathrm{OH}) \mathrm{D}$ level in elite male collegiate athletes. Change ratio of body fat 
percentage in athletes without vitamin D supplementation were significantly higher than those in athletes with vitamin D supplementation under the unexpected situation of ban in club activities due to the COVID-19 outbreak. The percentage of body fat is inversely related to the serum 25(OH)D level. Vitamin D supplementation might have preferable effect on maintaining athletes' body composition under circumstances where sports activity has decreased.

\section{Abbreviations}

BMI: Body mass index; COVID-19: Coronavirus disease 2019.

\section{Acknowledgements}

We would like to thank all the athletes and coaches for their interest and participation in this study.

\section{Authors' contributions}

IK conceptualized and drafted the article. IK and TT were the principal clinicians who explained to the participants and gathered the data. RK, IS, HH, and SI provided guidance for the literature search, the writing of the paper and also proof read the paper. TM provided guidance for analyze the data. All authors read and approved the final manuscript.

\section{Funding}

No funding was received for this research.

\section{Availability of data and materials}

The datasets used and/or analyzed during the current study are available from the corresponding author on reasonable request.

\section{Declarations}

Ethics approval and consent to participate

This report was approved by the Institutional Review Board and Ethics Committee of Asahi University.

\section{Consent for publication}

The authors have obtained the participants' written informed consent for print and electronic publication of this report.

\section{Competing interests}

The authors declare that they have no competing interests.

\section{Author details}

${ }^{1}$ Department of Orthopaedic Surgery, Nagoya University Graduate School of Medicine, 65 Tsurumai, Showa-ku, Nagoya, Aichi 466-8550, Japan. ²Department of Orthopaedic Surgery, Asahi University Hospital, 3-23 Hashimotocho, Gifu, Gifu 500-8523, Japan.

Received: 2 March 2021 Accepted: 14 May 2021

Published online: 21 May 2021

\section{References}

1. Angeline ME, Gee AO, Shindle M, Warren RF, Rodeo SA. The effects of vitamin D deficiency in athletes. Am J Sports Med. 2013;41:461-4.
2. Lappe J, Cullen D, Haynatzki G, Recker R, Ahlf R, Thompson K. Calcium and vitamin $D$ supplementation decreases incidence of stress fractures in female Navy recruits. J Bone Miner Res. 2008;23:741-9.

3. Ruohola JP, Laaksi I, Ylikomi T, Haataja R, Mattila VM, Sahi T, et al. Association between serum 25(OH)D concentrations and bone stress fractures in Finnish young men. J Bone Miner Res. 2006;21:1483-8.

4. Sterling JC, Edelstein DW, Calvo RD, Webb R 2nd. Stress fractures in the athlete: Diagnosis and management. Sports Med. 1992;14:336-46.

5. Ekstrand J, Torstveit MK. Stress fractures in elite male football players. Scand J Med Sci Sports. 2012;22:341-6.

6. Mehran N, Schulz MB, Neri RB, Robertson WJ, Limpisvasti O. Prevalence of vitamin D insufficiency in professional hockey players. Orthop J Sports Med. 2016;234:2325967116677512.

7. Hamilton B, Grantham J, Racinais S, Chalabi H. Vitamin D deficiency is endemic in Middle Eastern sportsmen. Public Health Nutr. 2010;13:1528-34.

8. Lovell G. Vitamin D status of females in an elite gymnastics program. Clin J Sport Med. 2008;18:159-61.

9. Cashman KD, Dowling KG, Škrabáková Z, Gonzalez-Gross M, Valtuena J, De Henaue S, et al. Vitamin D deficiency in Europe: pandemic? Am J Clin Nutr. 2016;103:1033-44.

10. American Academy of Pediatrics (Committee on Sports Medicine and Fitness) Promotion of healthy weight-control practices in young athletes. Pediatrics. 2005;116:1557-64.

11. Rontoyanni V, Avila J, Kaul S, Wong R, Veeranki SP. Association between obesity and serum 25(OH)D concentrations in older Mexican adults. Nutrients. 2017;9:97.

12. Yao Y, Zhu L, He L, Duan Y, Liang W, Nie Z, et al. A metaanalysis of the relationship between vitamin D deficiency and obesity. Int J Clin Exp Med. 2015:8:14977-84.

13. Zittermann A, Ernst JB, Gummert JF. Vitamin D supplementation, body weight and human serum 25-hydroxyvitamin D response: a systematic review. Eur J Nutr. 2014;53:367-74.

14. Golzarand M, Hollis BW, Mirmiran P, Wagner CL, Shab-Bidar S. Vitamin D supplementation and body fat mass: a systematic review and metaanalysis. Eur J Clin Nutr. 2018;72:1345-57.

15. Salehpour A, Hosseinpanah F, Shidfar F, Vafa M, Razaghi M, Dehghani $\mathrm{S}$, et al. A 12-week double-blind randomized clinical trial of vitamin $d_{3}$ supplementation on body fat mass in healthy overweight and obese women. Nutr J. 2012;11:78.

16. Kanda Y. Investigation of the freely available easy-to-use software "EZR" for medical statistics. Bone Marrow Transplant. 2013:48:452-8.

17. Holick MF. Vitamin D deficiency. N Engl J Med. 2007;357:266-81.

18. Jung HC, Seo MW, Lee S, Jung SW, Song JK. Correcting vitamin D insufficiency improves some, but not all aspects of physical performance during winter training in taekwondo athletes. Int J Sport Nutr Exerc Metab. 2018;28:635-43.

19. Renzo DL, Gualtieri P, Pivari F, Soldati L, Attina A, Cinelli G, et al. Eating habits and lifestyle changes during COVID-19 lockdown: an Italian survey. J Transl Med. 2020;18:229.

20. Arunabh S, Pollack S, Yeh J, Aloia JF. Body fat content and 25-hydroxyvitamin D levels in healthy women. J Clin Endocrinol Metab. 2003;88:157-61.

21. Worstman J, Matsuoka LY, Chen TC, Lu Z, Holick MF. Decreased bioavailability of vitamin D in obesity. Am J Clin Nutr. 2000;72:690-3.

22. Maruyama-Nagao A, Sakuraba K, Suzuki Y. Seasonal variations in vitamin D status in indoor and outdoor female athletes. Biomed Rep. 2016:5:113-7

\section{Publisher's Note}

Springer Nature remains neutral with regard to jurisdictional claims in published maps and institutional affiliations. 